\title{
The Skeleton Abnormalities in Patients with Neurofibromatosis Type 1: Important Consequences of Abnormal Gene Function
}

\author{
Marek W. Karwacki and Wojciech Wozniak \\ Nf-1 Outpatients Clinic E Department of Oncological Surgery for Children and Youth, \\ Institute of Mother and Child \\ Poland
}

\section{Introduction}

Neurofibromatosis type 1 [Nf-1, OMIM \#1622001], formerly known as von Recklinghausen disease, is one of the most frequent disorders affecting mankind, inherited as an autosomal dominant trait. The relatively high prevalence, with an incidence at birth of approximately one in 2500 to 3500 live births, and a progressive nature of the disorder, notable for its phenotypic variability with almost $100 \%$ penetrance, as well as high proportion of sporadic cases (almost $50 \%$ of de novo mutations), constitute for the clinical magnitude of this disease. Multiple café au lait spots [CALs], axillary and inguinal freckling, multiple discrete cutaneous neurofibromas [NFM] and more prominent plexiform neurofibromas [PNF], and iris Lisch nodules constituted for the cardinal signs of the disease. Learning disabilities and attention deficits states, but usually with normal intelligence in adulthood, are present in at least $50 \%$ of individuals with Nf-1. Neurofibromatosis type 1 belongs to the group of disorders with significantly increased risk of tumorigenesis. The other significant manifestations of Nf-1 include bone dysplasias, clinically presented as progressive dystrophic scoliosis, vertebral dysplasia, overgrowth and tibial dysplasia with pseudarthrosis, and vasculopathy. Pubertal development is usually normal, but precocious puberty, especially in those with an optic chiasm glioma, as well as delayed puberty, may commonly occur in children with Nf-1. The life expectancy of Nf-1 patients is assumed to be reduced by 15 years. The most important causes of early death in these patients are malignant peripheral nerve sheath tumors and severe complications of vasculopathy (Friedman et al., 1999; Jett \& Friedman, 2010; Larizza et al., 2009).

Despite the possibility of molecular testing, the diagnosis of Nf-1 is still based on clinical findings and is usually unequivocal in all but the young children (DeBella et al., 2000b). The diagnostic criteria for Nf-1 (Tabl. 1) were developed by the US National Institutes of Health (National Institute of Health [NIH], 1988) and are generally accepted worldwide for routine clinical use (Ferner et al., 2007; Williams et al., 2009). The disease is characterizes by extreme clinical variability, not only between unrelated, but also among affected individuals within a

\footnotetext{
${ }^{1}$ Online Mendelian Inheritance in Man, OMIM (TM). Johns Hopkins University, Baltimore, MD. MIM Number: \#162200, 07/06/2011. World Wide Web URL: http://www.ncbi.nlm.nih.gov/omim/
} 
single family carrying the same type of mutation, and even within a single person with Nf-1 at different times in life. Penetrance of NF1 gene mutation is virtually complete $(100 \%$ of penetration) after childhood and the frequency of more serious complications increases with age. Various manifestations of Nf-1 have different characteristic times of appearance (DeBella et al., 2000b; Boulanger \& Larbrisseau, 2005; Friedman ed., 1999; Williams et al., 2009). The clinical NIH diagnostic criteria are both highly specific and highly sensitive only in adults. Less than half of youngest children with no family history of Nf-1 meet NIH criteria, although almost all do by adolescence. Yet, neonates who inherited NF1 mutation from one of the parents can usually be identified within the first year of life by the presence of numerous CALs (DeBella et al., 2000b).

The presence of two or more of the following features is required for the diagnosis of Nf- 1 :

1. Six or more café au lait macules over $5 \mathrm{~mm}$ in greatest diameter in prepubertal individuals and over $15 \mathrm{~mm}$ in greatest diameter in postpubertal individuals

2. Two or more neurofibromas of any type, or one plexiform neurofibroma

3. Freckling in the axillary or inguinal regions

4. Optic glioma

5. Two or more Lisch nodules (iris hamartomas)

6. A distinctive osseous lesion such as sphenoid dysplasia or tibial pseudarthrosis

7. A first-degree relative (parent, sib, or offspring) with Nf-1 as defined by the above criteria

Table 1. The NIH diagnostic criteria for neurofibromatosis type 1

Neurofibromatosis type 1 is caused by heterozygous mutations (intragenic or microdeletion) in NF1 tumor suppressor gene, located at 17q11.2. Its product, neurofibromin, has different biochemical interactions, including association to microtubules and participation in several signaling pathways, especially as a member of the GTPase-activating proteins. Its main physiological function is inactivation of energized ras oncogene. NF1 mutation extinguish a gene function and leads to aberrant ras activity. NF1 gene belongs to the family of tumor suppressor genes and neurofibromatosis type 1 is thought to be a hereditary malignancy syndrome, which is highly influenced by complex action of other genes, required in signal transmission processing. In human diseases predisposing to cancer, cells usually carry heterozygous germline, what means inherited, mutations in growth regulator genes that are essential for organized cell growth and differentiation. Affected individuals, such as Nf-1 patients, are at significant risk for development of benign or malignant tumors early in life. In case of Nf-1, the most distinguished types of neoplasia are tumors arising from peripheral and optic nerves sheath (Schwann cells), usually benign neurofibroma and optic nerve glioma or seldom, malignant peripheral nerve sheath tumor [MPNST]. MPNST usually growths as a result of malignant transformation of plexiform neurofibroma [PNF], a specific, clinically distinguished type of neurofibroma. The risk of transformation of PNF into MPNST is not higher than $10 \%$, and have been finally evaluated in recent clinical trials (Upadhyaya, 2011). The overall risk of cancer development in Nf-1 patients surpass the healthy general population risk by 2.7 times (Walker et al., 2006). The risk of malignancy is higher in those patients because inherited nature of the first mutation released the entire process, and in consequence, only one additional acquire genetic alteration, resulted in loss of the wild allele of affected gene, is further necessary to facilitate tumorigenesis. In healthy 
individual both mutations must be acquire in intact alleles, so the chance for that is much lower. Cells that have lost both copies of the tumor suppressor gene have a growth advantage over so called wild cells. In a susceptible environment, this 'second hit' may result in tumor formation (Larizza et al., 2009; Upadhyaya, 2011). This helps to explain the development of neurofibromas and other malignancies occurring in Nf-1 patients, but currently does not fully explain the role of neurofibromin on the development of other ailments, and osseous abnormalities in particular. However the precise role of neurofibromin is not yet fully elucidated, although neurofibromin deficiency causes multiple clinical effects, suggesting that this gene product has diverse functions in a variety of tissues. Distorted process is responsible not only for tumorigenesis, but also for memory processing (intellectual disability) and bone remodeling (typical bone deformity seen in Nf-1 patients) (Radtke et al., 2007).

Phenotype expression of NF1 gene mutation is extremely variable, so even individuals from one family with identical germline mutation may have dramatically different clinical manifestations. Observed complexity and the diversity of constitutional NF1 mutations occurring in Nf-1 patients will continue to make genotype-phenotype correlation almost impossible. Clinical variability of Nf-1 results most probably from a combination of founder mutation effect of NF1 gene influenced by further action of other genes engaged in signal transduction, as well as other genetic, non-genetic, and stochastic factors (Jouhilahti et al., 2011). Till now more than 500 different mutations of the NF1 gene have been identified, and most of them are unique to a particular family. Different, mostly loss-of-function mutations, have been observed repeatedly, but none has been found in more than a few percent of studied families (Radtke et al., 2007). In consequence, there are not so called hot spots sequences manifest along the entire gene length, what significantly complicated not only molecular testing but genetic counseling as well. Till now, only two clear correlations have been observed between particular mutant NF1 alleles and consistent clinical phenotypes. In one, the whole NF1 gene deletion is associated with more prominent presentation of the disease (Mensink et al., 2006). In another, characterized by 3-bp in-frame deletion of exon 17 (c.2970-2972 delAAT), the typical pigmentary features, but no cutaneous or surface plexiform neurofibromas, exist (Upadhyaya et al., 2007). Data concerning NF1 mutation have accumulated slowly owing to the variability of the mutation types and the size and complexity of the gene, belongs to the longest in human genome. This also reflects the lack of a simple, inexpensive, highly accurate DNA-based test for Nf-1 at present (Radtke et al., 2007).

Currently no treatments dedicated specifically to Nf-1 patients exist. Because of the increased risk of cancer and multiorgan involvement, Nf-1 patients required extensive medical surveillance, provided on the regular bases by the specific, highly specialized Nf-1 clinics (Karwacki \& Wozniak, 2006). It obey a comprehensive standards, comprises of regular physical examination by a Nf-1 specialist, regular blood pressure and ophthalmologic monitoring, anthropometric and developmental assessment of children and periodical imaging, warrants follow-up of clinically suspected intracranial and other internal tumors, done by USG and/or MR imaging. CT scans are hardly recommended in NF-1 patients, but children in particular, as the imaging exerts the risk of irradiation and is of limited diagnostic value, especially in visualization of Nf-1 brain specific lesions, called undifferentiated bright objects [UBO](DeBella et al., 2000a). According to specific ailment, patients are referred by Nf-1 clinic to other specialists as well. 
The skeletal manifestations of a disease itself and the post-surgical bony complications occurred in Nf-1 patients, are common and have a prominent place in the orthopedic literature. The orthopedic complications of Nf-1, which usually appear early, include spinal deformities such as dystrophic scoliosis and kyphoscoliosis, congenital bowing and pseudoarthrosis of the tibia and the forearm, overgrowth phenomenon of the extremity, and soft tissue tumors, both benign and malignant (Crawford \& Schorry, 1999, 2006).

\section{Primary and secondary bone abnormalities in neurofibromatosis type 1}

Although phenotype of Nf-1 patients is well described, the osseous manifestations are rarely emphasized in the clinical and genetic discussions concerning the diseases. In fact, one of the seventh diagnostic NIH criterion represents a distinctive osseous defect. Nf- 1 is classically considers as a neurocutaneous disorder and clinical features of Nf-1 are classically thought of as neural crest in origin, but currently it is well accepted that mesodermally-derived abnormalities coexist as well. Restricted knowledge concerning the pathophysiology of Nf-1 skeletal abnormalities reflects the limited therapeutic modalities. Nf-1 is characterized by a multifaceted, polysystemic pathology. Among the other, bone involvement is representative for the majority of patients with Nf-1. The presentation of an ailment differs from patient to patient, but sometimes is extremely severe and appear from the birth or become evident either early in the childhood or further on and will accentuate with age. A number of skeletal involvements are highly morbid with a natural history distinct from that of the general population. A large proportion of patients with Nf-1 display primary skeletal involvement, including scoliosis and pseudoarthrosis, which are compounded by osteoporosis and poor bone healing (Crawford \& Schorry, 1999). In considerable proportion of patients, these bone lesions can result in significant morbidity. The natural history and pathogenesis of the skeletal abnormalities, resulted from alter NF1 gene function, are poorly understood. Consequently, therapeutic options for these ailments are currently limited. Corrective orthopedic intervention quite often fails necessitating multiple revision surgeries followed by prolonged recovery periods (Crawford \& Schorry, 2006).

Besides true dysplasia of bone, some of the skeletal changes observed in these patients are secondary to a tumor, compressing the bone through expansive growth, or its metastases. The most frequently, such tumors are plexiform neurofibromas, and rarely other malignancies occurred in Nf-1 more frequently than in general population, such as soft tissue sarcomas, notably rhabdomyosarcoma, and especially, malignant peripheral nerve sheath tumor [MPNST]. These tumors infiltrate easily in surrounding tissue, eroding the neighborhood bone, and frequently give rise to metastases, mostly to bones. Malignant peripheral nerve sheath tumor is an uncommon soft-tissue sarcoma [STS] that occurs at a higher incidence in patients with prior radiation exposure and Nf-1. MPNST resulted almost exclusively from the malignant transformation of PMF. It is assessed that every Nf-1 patient presenting PMF has a life time risk of 8 to $13 \%$ to develop a MPNST out of a pre-existing benign plexiform neurofibroma. In comparison to intragenic mutation, in patients with a NF1 microdeletion (5\% of Nf-1 patients) this risk is twice as high. That risk is even greater in patients, in whom PMFs were incorporated into the field of therapeutic radiotherapy performed as an component of complex oncological treatment. Irradiation is linked with much higher risk of such a transformation, and in some STS therapeutic protocols introduced to the clinic by oncological treatment groups is either contraindicated or introduced with caution, when offered to children with Nf-1. Most of MPNST, especially 
arising in Nf-1 patients, are considered high-grade sarcomas with the tendency to recur as well as to metastasize, typically to the lungs. It belongs to a group of malignancies of particularly worse prognosis and due to its rarity, there is a paucity of data concerning chemotherapy response of MPNST.

As the overall understanding of bone growth, remodeling, and repair dependent on NF1 gene function is critical to development of possible therapeutic interventions, in order to ensure continued collaboration and advancement toward better clinical management as well as effective drug therapies for Nf-1 related primary skeletal ailments, an International Nf-1 Bone Abnormalities Consortium have been convened in February 2008. The main goal of this Consortium is to identify barriers that might be impeding progression to future clinical trials for Nf-1 skeletal abnormalities and to highlights priorities for future research, based on animal model of Nf-1 related bone disease (Elefteriou et al., 2009).

\subsection{Skeletal abnormalities in humans: Clinical presentation, diagnosis, complications} The Nf-1 skeletal phenotypes might be either generalized or focal. Manifestation of generalized skeletal abnormalities, mostly osteopenia or osteoporosis and short stature, are common, but of mild clinical implications. Focal lesions, such as tibial dysplasia, short angle scoliosis, and sphenoid wing dysplasia, are less common, but usually cause significant morbidity.

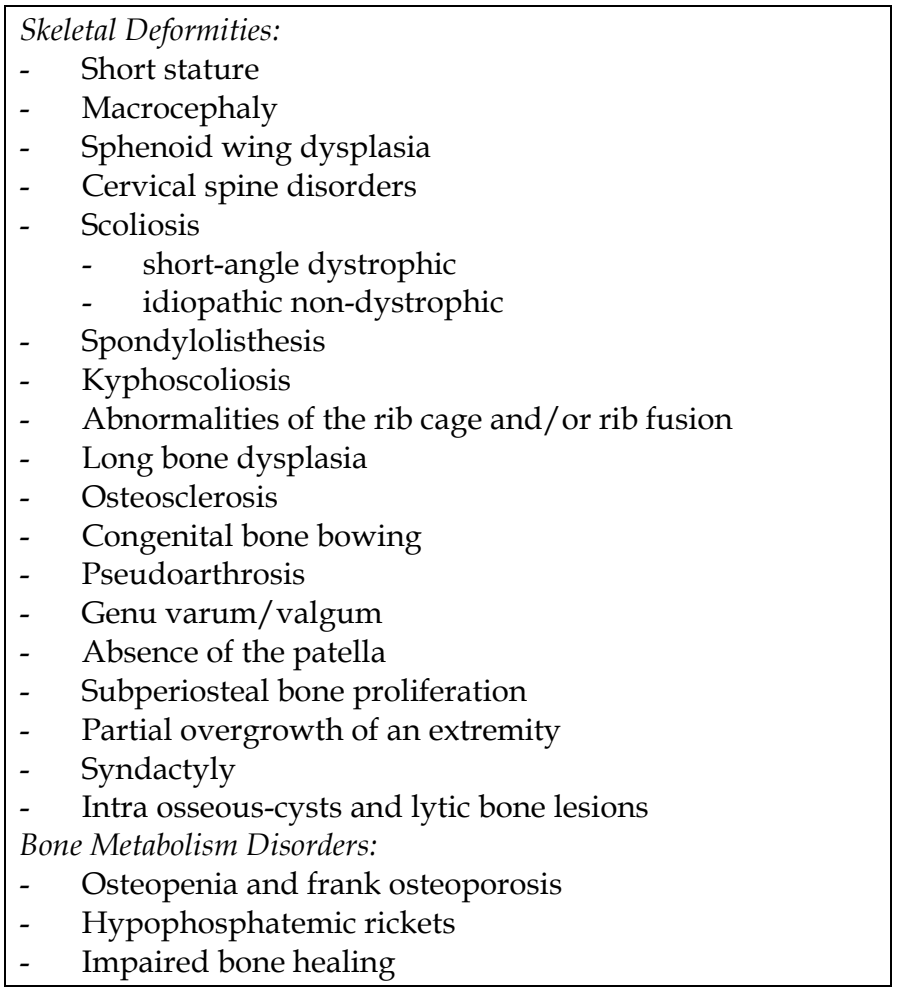

Table 2. Frequent manifestations of osseous abnormalities in patients suffering from Nf-1 


\subsubsection{Focal lesions: Spinal and chest wall deformations}

Spinal deformities frequently occur in individuals with Nf-1. These changes result from intra or perispinal pathology, such as tumors, or either meningoceles or dural ectasia. However, the deformities may be also present in persons with entirely normal intraspinal contents. In such patients, primary bone dysplasia accounts for the dystrophic vertebral changes.

The most frequent is scoliosis, and the most devastating form - kyphoscoliosis of progressive course regardless the intensive physiotherapy. In various series of Nf- 1 patients reported in the literature, frequency of scoliosis is assumed for 10 to 33\% (Crawford \& Herrera-Soto, 2007; Wang \& Liu, 2010). Vice versa, in general population, Nf-1 could be confirm in app. $2 \%$ of children suffering from scoliosis (Vitale et al., 2002). Orthopedic surgeons distinguished two types of spinal curvature disturbances in children with Nf-1: dystrophic and non-dystrophic. The cause of spinal deformity in Nf-1 is still a matter of debate, but some have suggested that it is secondary to endocrine disturbances observed in these patients, mesodermal dysplasia probably resulted from NF1 mutations, and osteomalacia, caused by a localized neurofibromatous tumor eroding and infiltrating adjacent bone.

The dystrophic scoliosis, usually associated with paravertebral neurofibromas, has a progressive nature and is associated with vertebral scalloping and wedging. Almost always develops before $10^{\text {th }}$ year of life (Crawford \& Herrera-Soto, 2007). Dystrophic scoliosis is often early onsetting, the shortsegmented, sharply angulated type of this ailment that includes fewer than 6 spinal segments. It has a tendency to progress to a severe deformity. The term dystrophic is usually used to describe a dysplastic vertebrae observed within scoliotic spine. Although there is no formal diagnostic criterion for such a form of scoliosis, Durrani et al. (2000) described nine specific radiographic features associated with dystrophic scoliosis (Tabl. 3).

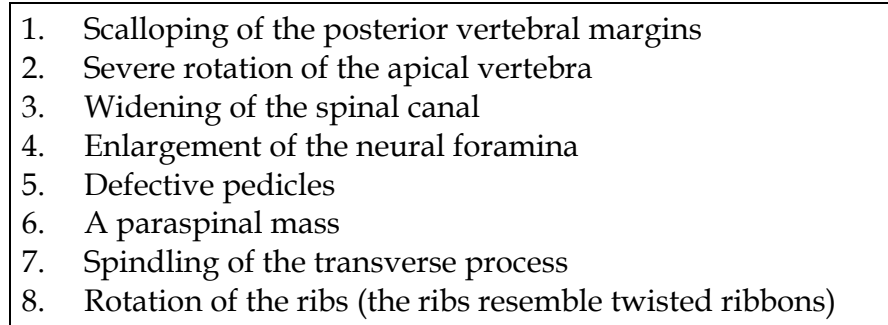

Table 3. The radiologic appearance of the dystrophic scoliosis (Durrani et al., 2000)

Distinctive radiographic features of dystrophic scoliosis, usually presented in the preadolescent child, include a short-segment sharply angulated curve (involving four to six vertebrae), scalloping of vertebral margins, vertebral wedging, spinal canal widening, defective pedicles, and rib-penciling (Crawford et al., 2007). It is potentially debilitating and may rapidly progress to neurological impairment. This kind of scoliosis is frequently associated with paraspinal or other internal neurofibromas adjacent to the vertebrae, which could be seen in app. 70\% of Nf-1 patients' MRI (Khong et al., 2003; Ramachandran et al., 2004). The complication of NFMs, or much frequently, PNFs penetrating into vertebral canal is dural ectasia, defined as widening of the dural sac surrounding the spinal cord, which might be seen in these patients (Khong et al., 2003; Schonauer et al., 2000; Tubbs and Oakes, 
2002). However, dural ectasia may be a primary mesodermal dysplasia of the meninges as well (Casselman and Mandell, 1979). The vertebral column can further displace or erode, causing rib dislocation into the spinal canal, resulting in spinal cord injury. Weakening of spinal natural stabilizers, such as facets, pedicles, and ligaments, usually distorted in Nf-1, may lead to kyphosis. Kyphoscoliosis and humpback is a severe complication of advanced dystrophic scoliosis and finally can lead to cardiorespiratory insufficiency and failure. In this point, the best and well known touching description of Nf-1 patient's suffering, given by Victor Hugo in "The Hunchback of Notre Dame", is worth to be remembered. Dystrophic scoliosis in Nf-1 patients is particularly difficult to treat and necessitates early aggressive surgical stabilization very often.

The other, milder form of scoliosis occurring in Nf-1 children, is called non-dystrophic. It is diagnosed typically during adolescence and resembles idiopathic adolescent scoliosis in healthy population (Crawford \& Herrera-Soto, 2007; Wang \& Liu, 2010). This form usually involves 8-10 spinal segments. The deformity is most often convex to the right; however, this is not consistent. In rare instances, non-dystrophic scoliosis can progress to the dystrophic form.

The presence of neurofibroma or abnormal pressure phenomena in and around the spinal canal neuraxis resulted in meningoceles, pseudomeningoceles, dural ectasia, and dumbbell lesions development.

Kyphosis in individuals with Nf-1 might be distinguished by acute anteroposterior angulation. Severe deformity of vertebral bodies in Nf-1 might be confused even with congenital deformities.

Chest wall deformities in patients with Nf-1 are observed even more frequently than scoliosis, and are thought to be present in as many as 50\% of patients (Riccardi, 2010). The relationship between chest wall deformities and scoliosis is not clear, but its existence exacerbates the course of dysplastic scoliosis in particular. It could happened, that chest wall deformities constitute the first clinical sign of tumor arising within the chest and quite often penetrating throughout the intervertebral foramina or dura mater. It resembles an hourglass shape, and is called spinal dumbbell tumor. This kind of growth is usually form by multiple tumors arose in the intradural and epidural spaces from one nerve root, occurring at the same time in different regions, such as the paravertebral, epidural and intradural spaces. Histopathological diagnosis is usually plexiform neurofibroma, but it still comprises the risk of malignant transformation into MPNST.

\subsubsection{Focal lesions: Head and neck region}

Increased head circumference is frequently observed in patients with Nf-1, and macrocephaly (head circumference $>2$ SD above the mean) occurs in about one-fourth of patients (Szudek et al., 2000). It is thought to be the consequence of brain enlargement (Greenwood et al., 2005). It is still not clear whether the skull growth contributes to macrocephaly. Contrariously, the association between macrocephaly and learning disabilities or underlying structural brain abnormalities has never been proof (Gutmann at al., 1997).

Sphenoid Wing Dysplasia Cranial defects attributed to the clinical pathology in Nf-1 with relatively lower frequency (eg. $11 \%$ had a dysplastic sphenoid wing in an observational study of Friedman and Birch (1997)). Sphenoid dysplasia usually is asymptomatic but occasionally can be associated with herniation through the bony defect. It is still under debate whether these type of changes reveal a primary bone dysplasia related to NF1 
mutation, or occur as secondary response of bone to the adjacent soft tissue abnormality. Most cranial defects are associated with plexiform neurofibromas of the eyelid or temporal region induced ipsilateral infiltration and decalcification of cranial bones adjacent to tumors (Jacquemin et al., 2002, 2003). Other lesions, including arachnoid cysts, dural ectasia, or buphthalmos, usually associate sphenoid wing defects. The suggestion of a bone cellautonomous defect, accounted for the dysplastic sphenoid wing, is based on two meaningful observations: (1) Nf-1 sphenoid wing lesions have been associated with tibial and vertebral dysplasia (Alwan et al., 2007), and (2) formation of this skull structure proceeds through endochondral bone formation, which is defective in Nf-1 (Kolanczyk et al., 2007). Regardless the cause, a congenital malformation or secondary bony defect, the sphenoid wing dysplasia is not currently a primary target for therapeutic prevention. Nevertheless, it is imperious necessity to apply sensitive imaging techniques to screen patients with sphenoid wing dysplasia for adjacent tumors, which may be amenable to therapy (Jacquemin, 2002, 2003).

Increased caries and early primary tooth eruption as well as periapical cemental dysplasia have been quite often reported in patients with Nf-1 (Lammert et al., 2007; Tucker et al., 2007; Visnapuu et al., 2007). Dental abnormalities in Nf-1 patients still require more attention, yet everyday practice pointed unnecessary dental procedures performed in these patients, for instance when periapical cemental dysplasia is confused with chronic inflammation on radiographic analysis and precipitate dental surgery.

Cervical spine abnormalities are due to cervical spine instability or intraspinal pathology, caused mostly by benign tumor. These occur much more frequently when a scoliosis or kyphoscoliosis is present in the thoracolumbar region, but could be omitted as the examiner's attention is focused on the more obvious deformity. Severe cervical kyphosis is the most common abnormality, which itself is highly suggestive for Nf-1 diagnosis. Patients usually had either limited motion or pain in the neck, which were probably attributed to cervical instability. The numerous, minor to major neurologic deficits, such as paraplegia, are present.

\subsubsection{Focal lesions: Long bones and extremities}

Long bone dysplasia appears in a small percentage (3-4\%) of patients with Nf-1 in clinicbased series (Friedman \& Birch, 1997) and tibia is involved most often among other long bones, which can be affected sparsely. Infant with such an ailment usually presents with unilateral anterolateral bowing of the lower leg, notably tibial, although a child may be born with fracture and/or pseudarthrosis as well, or develop these shortly after birth. The deformity may appear before other protean manifestations of $\mathrm{Nf}-1$, such as café-au-lait spots. The tibial bowing is usually evident within the first year of life, with a fracture not uncommonly occurring by age of 2-2.5 year. The tibial bowing associated with Nf-1 is always anterolateral. Affected bone is subject to pathologic fracture usually before age 3 years, often with minimal trauma. Subsequent healing may not occur normally, leading to consecutive non-union and pseudoarthrosis, sometimes requiring even amputation of affected extremity. As confirm histologically, the fibrous pseudarthrosis tissue seen at the fracture site is not a neurofibroma, but a fibrous overgrowth of unspecified cell origin. The ipsilateral fibula is often involved in association with tibial pseudoarthrosis and focal dysplasia of the ulna, radius, scapula, or vertebra may occur as well. The anterolateral bowing characterized patients with Nf-1 should be distinguished from the bilateral 
physiological bowing, exemplary common in children as they begin to walk or from the other type pathology.

Various radiographic classification systems for tibia bowing have been proposed, but they are still not rigorous and several subtypes represent rather changes over time, than the real variety. Nevertheless, tibial bowing in Nf-1 patients prior to fracture represents in radiograph a cortical thickening and medullary canal narrowing at the apex of the convexity, typically near the junction of the middle and distal thirds of the tibia (Stevenson et al., 2007).

In general, every bone of whatever kind and at any localization may usually be affected by the adjacent tumors as well, with all the consequences resemble the ones described above.

\subsubsection{Generalized skeletal abnormalities}

Although focal skeletal abnormalities, such as dystrophic scoliosis or tibial pseudoarthrosis and the like, can be severely disabling, they are uncommon among individuals with Nf- 1 . In contrary, generalized skeletal abnormalities are less severe but much more frequent in these patients. The osseous dysplasia result from disturbed bone growth, perhaps secondary to a mineralization disturbance. Findings such as decreased bone mineral density (BMD) and short stature reflect a generalized alteration of bone. The Nf-1 patients tend to be below average in height for age (below -2SD), although heights less than -3SD below the mean is seen hardly ever. Decreased BMD in both sexes at an early age has been reported in up to $50 \%$ of individuals with Nf-1. Reduced BMD in Nf-1 patients was initially recognized by Illes et al. (2001).

The exact pathogenesis of these bony changes is not understood, but patients with Nf-1 present lower than expected serum 25-hydroxyvitamin D (25OHD) concentrations, elevated serum parathyroid hormone concentration, and evidence of increased bone resorption. Defects in vitamin D metabolism, osteoclastogenesis or bone cell response to systemic signals regulating bone remodeling are likely involved. An inadequate increase in bone remodeling is also indirectly confirm by both bone histomorphometry and changes in circulating bone markers (Stevenson et al., 2008; Seitz et al., 2010). However, an increased incidence of fractures has not been firmly established. Still, generalized osteopenia and frank osteoporosis are more common than expected in patients with Nf-1. The results of one of the biggest series, in which Nf-1 children became the subject of multivariant analysis, indicate that the mean lumbar and whole body BMD z-scores were in the range of osteopenia and osteoporosis in $48 \%$ and $25 \%$ of subjects, respectively. BMD was reduced at multiple bone sites, while the lumbar spine being more severely affected (Brunetti-Pierri et al., 2008). A tumor inductive role has also been suggested (Ben-Baruch et al., 1994).

Several case reports from Nf-1 patients have identified histologically proven osteomalacia, which might be associated with hypophosphatemia due to renal phosphate wasting (AbdelWanis \& Kawahara, 2002). Although the concentration of baseline vitamin D were in the normal range in these patients, researchers further found that the osteomalacia can be reversed independently of phosphate supplementation with oral treatment of 1-alpha- $(\mathrm{OH})$ vitamin D3 (Konishi et al., 1991). Moreover, a recently published comparative study reported that 25OHD serum concentration were about twofold lower in the Nf-1 patients than in healthy population and were inversely correlated with the number of neurofibromas (Lammert et al., 2006). The exact underlying mechanism of vitamin D deficiency in Nf-1 patients still remains unclear as well as the value of vitamin D supplementation for the treatment of the patients is still poorly understood. 
Selected genetic disease populations, including $\mathrm{Nf}-1$, display increased risks for osteoporosis, which is an emerging complication of utmost importance. Early diagnosis in the pediatric population is essential, since the highest contribution to peak bone mass is attained in the first three decades. Osteopenia or decreased bone mass accrual in the pediatric period can lead to frank osteoporosis and fractures in adulthood in the general population, as peak bone density is generally reached by late adolescence. Emerging evidence shows that vitamin $\mathrm{D}$ deficiency combined with a higher than normal bone turnover contributes to decreased bone mineral density in patients with Nf-1. The results of currently published studies suggest that the population of Nf-1 patient is at an increased risk for the development of clinical complications related to osteoporosis.

Seldom but yet published data revealed that significantly lower blood concentration of osteocalcin was observed in Nf-1 patients with, in comparison with patients without, skeletal abnormalities. Osteocalcin is secreted by osteoblasts, plays a role in mineralization and calcium ion homeostasis and its level reflects the rate of bone formation. Reduced blood concentration of osteocalcin in Nf-1 patients with skeletal deformity may indicate defect in osteoblasts functioning. Other biochemical markers of bone turnover usually do not exhibit any difference between these groups (Duman et al., 2008). When compared to healthy subjects, in Nf-1 patients BMD of the lumbar spine and femoral neck is significantly decreased. The same significant decrease apply to pubertal patients when compared to pubertal controls and in prepubertal patients when compared to prepubertal controls. The decrease in BMD is still more pronounced in Nf-1 patients with severe scoliosis, than those without spinal deformities. Duman et al. (2008) suggests that relevant predictors of skeletal abnormalities among Nf-1 patients are bone formation markers (exclusively osteocalcin) rather than imaging (conventional radiography, CT, MRI or quantitative ultrasonometry of the calcaneal bone) and densitometry techniques, especially dual-energy X-ray absorptiometry (DXA). In opposite to this report, the other published data suggest that both DXA and quantitative ultrasonometry of the calcaneal or other bones may prove useful to identify individuals with NF1 who are at risk for clinical osseous complications. These techniques and the logistics, introduced into pediatric practice quite recently, may also be appropriate for monitoring of therapeutic trials concerning skeletal ailments in Nf-1 children. However, many significant heterogeneities among the reports in the literature, such as patient groups (ages, variability of skeletal involvements, etc.) and methods (BMD assaying, comparison criteria such as T-score, Z-score, their cutoff points, etc.) make the comparisons amongst the studies very difficult. The densitometric criterion commonly used as a predictor of fracture risk for osteoporotic adults, called T-scores, derived from reference populations of young-adult women. While useful for evaluation of fracture risk in adults, but especially in postmenopausal women, is not applicable to the diagnosis of osteoporosis in children. In this age period the evaluation of osteoporotic risk of fracture is much more difficult. Densitometric data in children must be compared with age-matched control populations (z-scores). Currently, it is generally accepted that z-scores below -1.5 indicate low bone mass or osteopenia, and that osteoporosis is suspected strongly with z-scores below -2 , especially followed by the episodes of fracturing. According to Writing Group for the ISCD Position Development Conference, z-score less than -2 define low bone density in children (2004).

According to unique published papers, children with Nf-1 had also statistically significant decreases in muscle mass compared to healthy controls regardless the presence or not of 
clinically proven osseous abnormalities (Stevenson et al., 2005). Muscle mass is important in the development of bone strength, as voluntary muscle forces (the largest physiological load) impact skeletal response. Combinations of extrinsic forces including decreased muscle mass could compromise potentially abnormal osseous matrix as well.

It is well known that NF1 gene is widely expressed in chondrocytes, osteoblasts, osteoclast, and osteocytes (Kuorilehto et al., 2004). Kuorilehto et al. (2004) reported as well that neurofibromin is expressed in growing cartilage in areas where proliferation has ceased and the chondrocytes are undergoing differentiation, and in periostealosteoblasts of embryonic and mature mice and rats. However, mechanism of various skeletal deformities and bone metabolism defects in Nf-1 patients are not clearly understood. Experimental work done on animal models suggest that patients with Nf-1 suffers from a bone formation defect rather than bone resorption.

\subsubsection{Other skeletal manifestations of neurofibromatosis type 1}

Individuals with Nf-1 tend to be shorter than expected for their families (Szudek et al., 2000; Virdis et al., 2003), with $20-30 \%$ of adults with NF1 estimated to have a height below the 3rd centile. Growth velocity in these individuals is typically normal or near normal before puberty, then declines. Short stature in patients with NF1 is usually proportional. Scoliosis, growth hormone deficiency, and other Nf-1 related complications can contribute to short stature, but the cause of this in most patients with Nf-1 is unknown.

Bony abnormalities may be clinically silent, with radiographic evidence of long bone intramedullary fibrosis, cortical thinning, or vertebral dural ectasias often found incidentally. Among the other bone abnormalities observed Nf-1 patients rarely, but with frequency a bit higher than in general populations, are cystic osseous lesions. They are usually identified incidentally during ongoing process of repeated imaging, reflecting the international recommendations. Found during radiographic knee exam, these cystic lesions are occasionally seen in the absence of tumors or long bone dysplasia (Colby \& Saul, 2003; Lee \& Cho, 2006). The lesions rarely fracture or show progressive deformity, and biopsy generally shows non-ossifying fibroma bone tumors. The association of multiple nonossifying fibromas with cafe au lait skin patches are the fundamental signs of JaffeeCampanacci syndrome (JCS) (Campanacci et al., 1983). The long bones affected more often are the femur, the humerus, and the tibia as well as the bones of the jaw. Other bones can be involved less frequently, especially the pelvis, the fibula, the radius, and the ulna. The lesions may be large enough to cause pathological fracture of the involved bone. Recent findings suggest that JCS may be a form of Nf-1 (Colby \& Saul, 2003).

\subsection{Pathophysiology of skeletal abnormalities in neurofibromatosis type 1: Experience from transgenic mouse models}

Studies assessing the role of NF1 gene not only in tumor formation and development, but also in pathogenesis of other multiple abnormalities, are to be a matter of numerous experimental work, which cannot be apply neither on living individuals, nor cell lines. These restrictions led to the development of transgenic mouse models allowing determination of the role of NF1 gene and its product in affected systems and facilitate preclinical studies. Unfortunately, mice's embryos with inactivated both NF1 alleles exhibit severe neural closure defect, namely exencephaly, and cardiovascular abnormalities including structural malformations of the outflow tract of the heart and enlarged 
endocardial cushions. These NF1-deficient embryos die between embryonic days 12.5 and 13.5, presumably due to the cardiac vessel defect. In contrast to completely defective organism, inactivation of only one allele of NF1 gene locally, in the neural crest only, does not cause cardiac defects but results in tumors of neural crest origin, resembling those seen in Nf-1 patients. Following this early experiments the another models of an experimental animal has been developed to determine the role of NF1 in bone cells and resolve difficulties in understanding the human pathophysiology of Nf-1 skeletal defects (Kolanczyk, 2007, 2008).

It has been well known that neurofibromin is a cytoplasmic protein that is predominantly expressed in neurons, Schwann cells, oligodendrocytes, astrocytes, and leukocytes. Due to early studies based on transgenic animal models of skeletal defective mice it is obvious currently that NF1-mRNA and neurofibromin are expressed in mouse bone and cartilage during development and adulthood (Kuorilehto et al., 2004), and more specifically in mesenchymal stem cells, chondrocytes, osteoblasts (Elefteriou et al., 2006; Kolanczyk et al., 2007), and osteoclasts (Yang et al., 2006a). Kuorilehto et al. (2004) reported the expression of neurofibromin in growth plate, periosteum, and tracebular bone of mice, and the expression in growth plate was mainly located in chondrocytes of the hypertrophic layer. $\mathrm{Yu}$ et al (2005) showed that upon the activation of ras signals, NF1+/- murine osteoprogenitor cells show increased proliferation and premature apoptosis; the osteoprogenitor cells also exhibit a lower rate of differentiation to osteoblasts. He considered neurofibromin and its role as ras signal regulator to be necessary for osteoblast function. Kolanczyk et al (2007) found that osteoblasts from NF1Prx1(NF1+/-) mice show increased proliferation and decreased abilities to differentiate and mineralize, whereas chondrocytes demonstrate a lower proliferation rate and defective differentiation. These results indicate that NF1 has multiple roles in skeletal development including joint formation, growth plate function, osteoblast differentiation, and control of vessel growth, and proved that NF1 is an important regulator of development and growth of the skeleton. The pattern of expression suggests that NF1related skeletal abnormalities stem in part from primary osseous defects caused by bone cellular dysfunctions related to generalized NF1 heterozygosity, and/or to NF1 loss of function in specific bone cell types.

Investigations of affected skeletal tissue in tibial pseudarthrosis model created by inactivation of one of NF1 alleles during early mouse limb development, confirm that further mutation of the second NF1 allele, thus the homozygous loss of NF1 function, was detrimental for normal bone development. Thus, like in NF1-mediated tumorigenicity, a loss of both NF1 alleles is likely to be required to cause the skeletal abnormality phenotype.

Available mouse models recapitulate some, but not all, of the bone abnormalities in patients with Nf-1. Mouse data helped clarify that NF1 haploinsufficiency is likely related to the generalized Nf-1 bone remodeling defects, whereas total loss of NF1 function is likely related to the focal dysplastic events. Identifying neurofibromin cellular functions, target genes and downstream signaling pathways remains a priority to understand the etiology of the Nf-1 skeletal manifestations.

\section{Present day and future treatment of skeletal dysplasia in neurofibromatosis type 1}

Consensus guidelines for the treatment of the specific orthopedic manifestations in patients with Nf-1 do not exist and clinical management practices for each Nf-1 skeletal abnormality varied considerably. 
At present, there are either no clinical trials to support the use of osteoporotic drugs in a population of Nf-1 patients or treatment guidelines. Thus, conservative therapy to promote bone health, such as treatment with calcium and vitamin D, and weight-bearing exercise forms the first line of therapy in children with Nf-1 and low bone mass. Correction of measured deficiencies in hormones (vitamin D, thyroid, estrogen, etc.) that are known to regulate skeletal growth and maturation is inevitable. Judicious vitamin D supplementation may prove beneficial for patients with Nf-1 who have vitamin D deficiency or evidence of osteopenia. Similarly, until further information is obtained, treatment of osteoporosis in adults with Nf-1 follow the recommendations developed for general population. Because low serum 25-OH-D and osteomalacia has been reported in patients with Nf-1 and low bone mass, osteoporotic adult patients over age 50 years should take supplemental 1,200 mg calcium and 800-1,000 IU vitamin D per day, and reduce clinical risk factors by regular weight bearing and muscle strengthening exercises and avoidance of smoking and excessive alcohol. Selection of approved anabolic or anti-resorptive drugs to prevent or treat osteoporotic fractures should follow the standard practice with exception of children. Children should be treated as well, as soon as fracture complicates the osteopenic/osteoporotic bone dysplasia (Elefteriou, 2009). Unfortunately, anabolic substances available currently upon two forms of parathyroid hormone pose the increased risk of osteosarcoma development, proven in rats, and are contraindicated in children (Tashjian \& Gagel, 2006). Bisphosphonates and monoclonal antibodies that target osteoclasts, belonging to anti-resorptive drugs, have been used to reduce osteoporotic fractures in adults, but their effect on BMD and fracture risk in children with Nf-1 is unknown. Clinical trials are necessary to determine which of currently available therapies are most effective to treat patients with $\mathrm{Nf}-1$ and reduces BMD, but especially frank osteoporosis.

In patients with $\mathrm{Nf}-1$, the morbidity associated with either dystrophic scoliosis or tibial dysplasia is much greater than that of osteopenia and osteoporosis or even non-dystrophic scoliosis. This helps define priorities for current and future trials. Some of the ailments, particularly dystrophic scoliosis or tibial bowing, can lead to clinically significant consequences if neglected.

Children with dystrophic scoliosis require the extensive medical attention. In children who do not complete skeletal maturation, typically presented dystrophic form of scoliosis, bracing is routinely used when the spine curvature exceeded 25 up to 45 degrees. While the curvature progresses to more than 45 degrees before maturity or 55 degrees after maturity, surgery is commonly employed. Unique management approach due to progression is necessary in skeletally immature patients with dystrophic scoliosis in whom a curvature exciding 30 degrees. Exclusion of paravertebral tumors and dystrophic changes required MR or, less sensitive, CT imagings, as those finding may be missed on plain radiographs. Regarding possible complications of surgery, careful presurgical assessment is critical, as the lamina may be thin, the canal affected by dural ectasia or intraspinal tumors, and a rib may have displaced into the spinal canal, all of which express an increased risk of poor postsurgical outcome. Variables such as age, gender, associated neurofibromas, location and degree of the curve, and associated radiographic dystrophic features make the operation design difficult. Surgical treatment with fusion and growing rods is complex. Occasionally, intraspinal elements may directly compromise the cord when instrumentation and stabilization are attempted, or they may cause erosive changes in the bone, preventing 
primary fusion. The local condition may exclude the possibility of radical excision of tumor not infrequently, additionally worsen the postsurgical outcome. A lack of animal models of dystrophic scoliosis and consequently poor understanding of the natural history of this ailment, additionally hinder progress. As the pathogenesis of Nf- 1 dystrophic scoliosis is still poorly understood, there are no clear pharmacologic adjunctive options. It is postulated, that prospective studies to determine the relationship of spinal neurofibromas in patients with dystrophic scoliosis may help to determine if early treatment of spinal tumors could prevent dystrophic scoliosis. Currently there is no effective treatment for Nf- 1 related dural ectasia. If microfractures and vertebral wedging with subsequent development of scoliosis is diagnosed, then pharmacologic agents to increase vertebral strength may be appropriate (Elefteriou, 2009).

The dumbbell tumors, most of which are located unilaterally in the spinal canal and paravertebral space, are excised through a hemilaminectomy and a facetectomy, because these techniques provide large space for tumors excision. In addition, the spinal stability can be reconstructed by Rogers wiring and contralateral facet fusion, because the hemilaminectomy and facetectomy can minimize damage to spinal stability by leaving the spinous process, supra- and intraspinous ligaments, and contralateral facet joint.

Some dermal and most often internal plexiform neurofibromas, generally larger, more diffuse, and locally invasive to adjacent tissue and bone are seen in more than one fourth of patients with Nf-1 and can present a surgical or medical management conundrum. Besides pain, disfigurement, neurological and other clinical deficits complicated its growth, the wisdom of watchful waiting versus aggressive intervention is often debated (Wozniak \& Karwacki, 2008). Complete resection of a PNF, radicalism of which is always controversial, without residual functional deficits is rarely possible, on the other hand, it must be remembered that app. $10 \%$ of them undergo malignant transformation. Thus debulking or partial resection of PNF may be undertaken not only for cosmetic purposes, but especially when progressive functional consequences are anticipated.

Surgical treatment of the chest wall deformities is usually not required, and the ailment, as well as short but proportional stature and not prominent macrocephaly, are assumed as principally cosmetic.

Sphenoid wing dysplasia, comprising a congenital malformation or a secondary bony defect, is not a primary target for therapeutic prevention. Although, it requires sensitive imaging techniques, particularly MRI, to screen patient for adjacent tumor, which may be amenable to therapy.

The management of anterolateral bowing deformity, characteristic for Nf-1, is most frustrating. Unlike scoliosis, treatment of congenital pseudarthrosis of the tibia does not appear to be more successful when it is initiated early. Anecdotally, early surgical intervention in children with Nf-1 and tibial pseudarthrosis results in poorer outcomes compared to later surgical management. The Consortium orthopedists recommended routine bracing of the dysplastic long bone upon diagnosis of bowing and agreed that prophylactic surgery should be avoided (Elefteriou, 2009). So, the current standard for treatment of long bone bowing in children is bracing to prevent fracture. The majority of members of the Consortium advocated early bracing until the child achieves maturity and, in some cases, continued even into adulthood. Evaluations of brace type, duration of use, or long-term benefits have not been obvious. Treatment of long bone pseudarthrosis is often unsatisfactory and very often require multiple surgeries or ultimate amputation. It is general 
belief that bracing after pathological fracture should continue, delaying surgery until midchildhood, in fifth - eight year of age at earliest. Among the surgical procedures the most often applied are resection of the pseudarthrotic region and bone bridging with fixation via intramedullary stabilization devices, or free vascularized fibular grafting (contralateral or ipsilateral), or external fixation (e.g., Ilizarov technique), either alone or in combination with transankle fixation. Residual angular deformity, ankle stiffness, limb length discrepancy, refracture, and chronic pain are amongst the most severe complications of long bone pseudarthrosis. Attempts must been made to promote bone healing, always impaired in children with Nf-1 affected bones. Thus, electrical stimulation, varying periods of postoperative immobilization, supplemental bone grafting, and more sophisticated techniques, such as application of bone morphogenetic proteins and monocytic progenitors stem cells are under the routine or experimental options. Summarizing, tibial dysplasia with pseudarthrosis is still challenging Nf-1 skeletal manifestation required further extensive elaboration, on both scientific and everyday practice fields (Elefteriou, 2009).

Established transgenic mouse models of NF1 gene and its protein dysfunctions opens up new vistas for a better understanding of the natural history and the development of new therapies and long-term orthopedic management essential to improve patient care. Based on data from these models, a variety of cell types and signaling pathways are likely to be involved in Nf-1 patients with bone manifestations. Therefore, combination therapies, using both anabolic and anti-catabolic medications, will likely give optimal results. For example, use of locally applied biological mediators (e.g., bone morphogenetic protein) at the time of surgery in patients with pseudarthrosis is an attractive option in order to avoid complications of systemic administration of pharmacologic agents. Unfortunately, no mouse model, even closely resembles the human skeletal manifestations, is fully identical, despite similarities with the human condition, in part due to the limitations of the genetic manipulations. Nevertheless, NF1-deficient mice are currently the only and highly valuable project in preclinical testing of candidate therapies for Nf-1 skeletal defects.

Various studies have been initiated until now in preclinical mouse models to assess the potential efficacy of selected drugs on bone formation, repair and remodeling. Even when they represent just an initial approach, the most promising demonstrated potential of bisphosphonates (such as zolendronic acid) and recombinant human bone morphogenetic proteins (rhBMPs), which induces bone and cartilage formation, for improved net bone production in an in vivo model of heterotopic bone formation (Schindeler et al., 2008, Schindeler et al., 2011). Bisphosphonates are currently approved for other applications, so they could transition rapidly to Nf-1 clinical trials. Kolanczyk et al. (2008) quite recently published data concerning lovastatin, which improves cortical bone injury healing defects observed in the NF1-deficient mice. The inhibition of Ras/Erk signaling by lovastatin and other statins in mouse model counteracts the Ras/Erk constitutive activation occurred in NF1-deficient osteoblasts (as in Schwann cells), and improves bone healing defects. His work established the base for future experiments aimed at the treatment of the focal Nf-1 bone changes with local statin's delivery (Weixi et al., 2010).

\section{Final remarks and conclusions for the future}

Although neurofibromatosis type 1 is associated with marked clinical variability, most affected children do well from the standpoint of their growth and development. Some features of Nf-1 are present at birth, and others are age related abnormalities of tissue 
proliferation, which necessitate periodic monitoring to address ongoing health and developmental needs and to minimize the risk of serious medical complications. Among the most important and often debilitating are skeletal abnormalities. The skeleton is frequently affected in individuals with Nf-1, and some of these bone manifestations can result in significant morbidity and even profound invalidism. The natural history and pathogenesis of these skeletal abnormalities are still poorly understood and consequently therapeutic options for these manifestations are currently limited. Lately established transgenic mouse models as well as continuously developing new and improved imaging techniques warrants further achievements either in basic science concerning the complications of NF1 mutation or clinical availability of diagnostic tools. The ongoing investigational trials, both preclinical and clinical as well as observational, gather significant number of participants, strengthen patient's belief for future improved care and therapy potentially freed them from often burdensome complications of disease course.

\section{References}

Abdel-Wanis, M. \& Kawahara, N. (2002). Hypophosphatemic osteomalacia in neurofibromatosis type 1: hypotheses for pathogenesis and higher incidence of spinal deformity. Med Hypotheses. Vol. 59, No. 2, pp. 183-185

Alwan, S., Armstrong, L., Joe, H., Birch, P.H., Szudek, J. \& Friedman, J.M. (2007). Associations of osseous abnormalities in Neurofibromatosis 1. Am J Med Genet, Part A. Vol. 143A, No. 12, pp. 1326-1333

Ben-Baruch, D., Ziv, Y., Sandbank, J. \& Wolloch, Y. (1994). Oncogenic osteomalacia induced by schwannoma in a patient with neurofibromatosis. Eur J Surg Oncol. Vol. 20, No. 1, pp. 57-61

Boulanger, J.M. \& Larbrisseau, A. (2005). Neurofibromatosis type 1 in a pediatric population: Ste-Justine's experience. Can J Neurol Sci. Vol. 32, No. 2, pp. 225-231

Brunetti-Pierri, N., Doty, S.B., Hicks, J., Phan, K., Mendoza-Londono, R., Blazo, M., Tran, A., Carter, S., Lewis, R.A., Plon, S.E., Phillips, W.A., O'Brian Smith, E., Ellis, K.J. \& Lee, B. (2008). Generalized metabolic bone disease in neurofibromatosis type I. Mol Genet Metab. Vol. 94, No. 1, pp. 105-111

Campanacci, M., Laus, M. \& Boriani, S. (1983). Multiple non-ossifying fibromata with extraskeletal anomalies: a new syndrome? J Bone Joint Surg Br. Vol. 65, No. 5, pp. 627-32

Casselman, E.S. \& Mandell, G.A. (1979). Vertebral scalloping in neurofibromatosis. Radiology. Vol. 131, No. 1, pp. 89-94

Colby, R.S. \& Saul, R.A. (2003). Is Jaffe-Campanacci syndrome just a manifestation of neurofibromatosis type 1 ? Am J Med Genet. Vol. 15, No. 1, pp. 60-3

Crawford, A.H. \& Schorry, E.K. (1999). Neurofibromatosis in children: The role of the orthopaedist. J Am Acad Orthop Surg.Vol. 7, No. 4, pp. 217-230

Crawford, A.H. \& Schorry, E.K. (2006). Neurofibromatosis update. J Pediatr Orthop. Vol. 26, No. 3, pp. 413-23

Crawford, A.H. \& Herrera-Soto, J. (2007). Scoliosis associated with neurofibromatosis. Orthop Clin North Am. Vol. 38, No. 4, pp. 553-62

Crawford, A.H., Parikh, S., Schorry, E.K. \& Von Stein, D. (2007). The immature spine in type-1 neurofibromatosis. J Bone Joint Surg Am Vol. 89, Suppl. 1, pp. 123-142 
DeBella, K., Poskitt, K., Szudek, J. \& Friedman, J.M. (2000a). Use of “unidentified bright objects" on MRI for diagnosis of neurofibromatosis 1 in children. Neurology Vol. 54, No. 8, pp. $1646-1651$

DeBella, K., Szudek, J. \& Friedman, J.M. (2000b). Use of the national institutes of health criteria for diagnosis of neurofibromatosis 1 in children. Pediatrics. Vol. 105, No. 3 , Pt. 1, pp. 608-614

Duman, O., Ozdem, S., Turkkahraman, D., Olgac, N.D., Gungor, F. \& Haspolat, S. (2008). Bone metabolism markers and bone mineral density in children with neurofibromatosis type-1. Brain \& Development. Vol. 30, No. 9, pp. 584-588

Durrani, A.A., Crawford, A.H., Chouhdry, S.N., Saifuddin, A. \& Morley, T.R. (2000). Modulation of spinal deformities in patients with neurofibromatosis type 1. Spine (Phila Pa 1976). Vol. 25, No. 1, pp. 69-75.

Elefteriou F., Benson, M.D., Sowa, H., Starbuck, M., Liu, X., Ron, D., Parada, L.F. \& Karsenty, G. (2006). ATF4 mediation ofNF1 functions in osteoblast reveals a nutritional basis for congenital skeletal dysplasiae. Cell Metab Vol. 4, No. 6, pp. 441-451

Elefteriou, F., Kolanczyk, M., Schindeler, A., Viskochil, D.H., Hock, J.M., Schorry, E.K., Crawford, A.H., Friedman, J.M., Little, D., Peltonen, J., Carey, J.C., Feldman, D., Yu X., Armstrong, L., Birch, P., Kendler, D.L., Mundlos, S., Yang, F.C., Agiostratidou, G., Hunter-Schaedle K. \& Stevenson D.A. (2009). Skeletal abnormalities in neurofibromatosis type 1: approaches to therapeutic options. Am J Med Genet A. Vol. 149A, No. 10, pp. 2327-38

Ferner, R.E., Huson, S.M., Thomas, N., Moss, C., Willshaw, H., Evans, D.G., Upadhyaya, M., Towers, R., Gleeson, M., Steiger, C. \& Kirby A. (2007). Guidelines for the diagnosis and management of individuals with neurofibromatosis 1 (NF1). J Med Genet Vol. 44 , No. 2, pp. $81-88$

Friedman, J.M., Gutmann, D.H., MacCollin, M. \& Riccardi, V.M. (Eds.)(1999). Neurofibromatosis: phenotype, natural history, and pathogenesis. Johns Hopkins University Press, ISBN: 080186285X, Baltimore MD

Friedman JM \& Birch PH. Type 1 neurofibromatosis: a descriptive analysis of the disorder in 1,728 patients. Am J Med Genet. 1997 May 16;70(2):138-43

Greenwood, R.S., Tupler, L.A., Whitt, J.K., Buu, A., Dombeck, C.B., Harp, A.G., Payne, M.E., Eastwood, J.D., Krishnan, K.R. \& MacFall J.R. (2005). Brain morphometry, T2weighted hyperintensities, and IQ in children with neurofibromatosis type 1 . Arch Neurol. Vol. 62, No. 12, pp. 1904-1908

Gutmann, D.H., Aylsworth, A., Carey, J.C., Korf, B., Marks, J., Pyeritz, R.E., Rubenstein, A., Viskochil, D. (1997). The diagnostic evaluation and multidisciplinary management of neurofibromatosis 1 and neurofibromatosis 2, JAMA. Vol. 278, No. 1, pp. 51-57.

Illes, T., Halmai, V., de Jonge, T. \& Dubousset, J. (2001). Decreased bone mineral density in neurofibromatosis-1 patients with spinal deformities. Osteoporos Int. Vol. 12, No. 10, pp. 823-827

Jacquemin, C., Bosley, T.M., Liu, D., Svedberg, H. \& Buhaliqa, A. (2002). Reassessment of sphenoid dysplasia associated with neurofibromatosis type 1. Am J Neuroradiol. Vol. 23, No. 4, pp. 644-648

Jacquemin, C., Bosley, T.M. \& Svedberg, H. (2003). Orbit deformities in craniofacial neurofibromatosis type 1. Am J Neuroradiol. Vol. 24, No. 8, pp. 1678-1682 
Jett, K. \& Friedman, J.M. (2010). Clinical and genetic aspects of neurofibromatosis 1. Genet Med. Vol. 12, No 1, pp. 1-11

Jouhilahti, E.M., Peltonen, S., Heape, A.M. \& Peltonen, J. (2011). The pathoetiology of neurofibromatosis 1. Am J Pathol. Vol. 178, No. 5, pp. 1932-9

Karwacki, M.W. \& Wozniak, W. (2006). Neurofibromatosis--an inborn genetic disorder with susceptibility to neoplasia. Med Wieku Rozwoj. Vol. 10, No. 3, Pt. 2, pp. 923-48

Khong, P.L., Goh, W.H., Wong, V.C., Fung, C.W. \& Ooi, G.C. (2003). MR imaging of spinal tumors in children with neurofibromatosis 1 . Am J Roentgenol. Vol 180, No. 2, pp. 413-417.

Kolanczyk, M., Kossler, N., Kuhnisch, J., Lavitas, L., Stricker, S., Wilkening, U., Manjubala, I., Fratzl, P., Sporle, R., Herrmann, B.G., Parada, L., Kornak, U. \& Mundlos S. (2007). Multiple roles for neurofibromin in skeletal development and growth. Hum Mol Genet. Vol. 16, No. 8, pp. 874-886

Kolanczyk, M., Kuehnisch, J., Kossler, N., Osswald, M., Stumpp, S., Thurisch, B., Kornak, U. \& Mundlos, S. (2008). Modelling neurofibromatosis type 1 tibial dysplasia and its treatment with lovastatin. BMC Med. No. 6, p. 21.

Konishi, K., Nakamura, M., Yamakawa, H., Suzuki, H., Saruta, T., Hanaoka, H. \& Davatchi, F. (1991). Hypophosphatemic osteomalacia in von Recklinghausen neurofibromatosis. Am J Med Sci. Vol. 301, No. 5, pp. 322-328

Kuorilehto, T., Nissinen, M., Koivunen, J., Benson, M.D. \& Peltonen, J. (2004). NF1 tumor suppressor protein and mRNA in skeletal tissues of developing and adult normal mouse and NF1-deficient embryos. J Bone Miner Res. Vol. 19, No. 6, pp. 983-9

Lammert, M., Friedman, J.M., Roth, H.J., Friedrich, R.E., Kluwe, L., Atkins, D., Schooler, T., Mautner, V.F. (2006). Vitamin D deficiency associated with number of neurofibromas in neurofibromatosis 1. J Med Genet. Vol. 43, No. 10, pp. 810-3

Lammert, M., Friedrich, R.E., Friedman, J.M., Mautner, V.F., Tucker T. (2007). Early primary tooth eruption in neurofibromatosis 1 individuals. Eur J Oral Sci. Vol. 115, No. 5, pp. 425-426

Larizza, L., Gervasini, C., Natacci, F. \& Riva, P. (2009). Developmental abnormalities and cancer predisposition in neurofibromatosis type 1. Curr Mol Med. Vol. 9, No. 5, pp. 634-53

Lee, H.C. \& Cho, D.Y. (2006). Assessment of sacrum scalloping in neurofibromatosis type 1 caused by a giant cell lesion of the sacrum. Surg Neurol Vol. 65, No. 2, pp. 194-198 (discussion $\mathrm{p}$ 198)

Mensink, K.A., Ketterling, R.P., Flynn, H.C., Knudson, R.A., Lindor, N.M., Heese, B.A., Spinner, R.J. \& Babovic-Vuksanovic, D. (2006). Connective tissue dysplasia in five new patients with NF1 microdeletions: further expansion of phenotype and review of the literature. J Med Genet. Vol. 43, No. 2, p. e8

Neurofibromatosis. Conference statement. National Institutes of Health Consensus Development Conference. (1988). Arch Neurol. Vol. 45, No. 5, pp. 575-8

Ramachandran, M., Tsirikos, A.I., Lee, J. \& Saifuddin, A. (2004). Whole-spine magnetic resonance imaging in patients with neurofibromatosis type 1 and spinal deformity. J Spinal Disord Tech. Vol. 17, No. 6, pp. 483-491

Radtke, H.B., Sebold, C.D., Allison, C., Haidle, J.L. \& Schneider, G. (2007). Neurofibromatosis type 1 in genetic counseling practice: recommendations of the National Society of Genetic Counselors. J Genet Couns. Vol. 16, No. 4, pp. 387-407 
Riccardi, V.M. (2010). Neurofibromatosis type 1 is a disorder of dysplasia: the importance of distinguishing features, consequences, and complications. Birth Defects Res A Clin Mol Teratol. Vol. 88, No.1, pp. 9-14

Schindeler, A., Ramachandran, M., Godfrey, C., Morse, A., McDonald, M., Mikulec, K. \& Little, D.G. (2008). Modeling bone morphogenetic protein and bisphosphonate combination therapy in wild-type and Nf1 haploinsufficient mice. J Orthop Res. Vol. 26, No. 1, pp. 65-74

Schindeler, A., Birke, O., Yu, N.Y., Morse, A., Ruys, A., Baldock, P.A. \& Little, D.G. (2011). Distal tibial fracture repair in a neurofibromatosis type 1-deficient mouse treated with recombinant bone morphogenetic protein and a bisphosphonate. J Bone Joint Surg Br. Vol. 93, No. 8, pp. 1134-9

Schonauer, C., Tessitore, E., Frascadore, L., Parlato, C. \& Moraci, A. (2000). Lumbosacral dural ectasia in type 1 neurofibromatosis. Report of two cases. J Neurosurg Sci Vol. 44, No. 3, pp. 165-168 (and discussion p. 169)

Seitz, S., Schnabel, C., Busse B., Schmidt, H.U., Beil, F.T., Friedrich, R.E., Schinke, T., Mautner, V.F. \& Amling, M. (2010). High bone turnover and accumulation of osteoid in patients with neurofibromatosis 1. Osteoporos Int. Vol. 21, No. 1, pp. $119-27$

Stevenson, D.A., Moyer-Mileur, L.J., Carey, J.C., Quick, J.L., Hoff, C.J. \& Viskochil, D.H. (2005). Case-control study of the muscular compartments and osseous strength in neurofibromatosis type 1 using peripheral quantitative computed tomography. J Musculoskelet Neuronal Interact. Vol. 5, No. 2, pp. 145-9

Stevenson, D.A., Moyer-Mileur, L.J., Murray, M., Slater, H., Sheng, X., Carey, J.C., Dube, B. \& Viskochil, D.H. (2007). Bone mineral density in children and adolescents with neurofibromatosis type 1. J Pediatr. Vol. 150, No. 1, pp. 83-88

Stevenson, D.A., Schwarz, E.L., Viskochil, D.H., Moyer-Mileur, L.J., Murray, M., Firth S.D., D'Astous, J.L., Carey, J.C. \& Pasquali, M. (2008). Evidence of increased bone resorption in neurofibromatosis type 1 using urinary pyridinium crosslink analysis. Pediatr Res. Vol. 63, No. , pp. 697-701

Szudek, J., Birch, P. \& Friedman, J.M. (2000). Growth in North American white children with neurofibromatosis 1 (NF1). J Med Genet Vol. 37, No. 12, pp. 933-938

Tashjian A.H. Jr. \& Gagel R.F. (2006). Teriparatide [human PTH(1-34)]: 2.5 years of experience on the use and safety of the drug for the treatment of osteoporosis. J Bone Miner Res. Vol. 21, No. 3, pp. 354-65

Tubbs, R.S. \& Oakes, W.J. (2002). Dural ectasia in neurofibromatosis. Pediatr Neurosurg. Vol. 37, No. 6, pp. 331-332

Tucker, T., Birch, P., Savoy, D.M. \& Friedman, J.M. (2007). Increased dental caries in people with neurofibromatosis 1 . Clin Genet. Vol. 72, No. 6, pp. 524-7

Upadhyaya, M. (2011). Genetic basis of tumorigenesis in NF1 malignant peripheral nerve sheath tumors. Front Biosci. Vol. 16 (Jan. 1, 2011), pp. 937-51

Upadhyaya, M., Huson S.M., Davies, M., Thomas, N., Chuzhanova, N., Giovannini, S., Evans, D.G., Howard, E., Kerr, B., Griffiths, S., Consoli C., Side, L., Adams, D., Pierpont., M., Hachen, R., Barnicoat, A., Li, H., Wallace, P., Van Biervliet, J.P., Stevenson, D., Viskochil, D., Baralle, D., Haan, E., Riccardi, V., Turnpenny P., Lazaro, C. \& Messiaen, L. (2007). An absence of cutaneous neurofibromas associated with a 3-bp inframe deletion in exon 17 of the NF1 gene (c. 2970-2972 
delAAT): evidence of a clinically significant NF1 genotype-phenotype correlation. Am J Hum Genet. Vol. 80, No. 1, pp. 140 -151.

Virdis, R., Street, M.E., Bandello, M.A., Tripodi, C., Donadio, A., Villani, A.R., Cagozzi, L., Garavelli, L. \& Bernasconi, S. (2003). Growth and pubertal disorders in neurofibromatosis type 1. J Pediatr Endocrinol Metab. Vol. 16, Suppl. 2, pp. 289-292

Visnapuu, V., Peltonen, S., Ellila, T., Kerosuo, E., Vaananen, K., Happonen, R.P. \& Peltonen, J. (2007). Periapical cemental dysplasia is common in women with NF1. Eur J Med Genet. Vol. 50, No. 4, pp. 274-280

Vitale, M.G., Guha A. \& Skaggs D.L. (2002). Orthopaedic manifestations of neurofibromatosis in children: an update. Clin Orthop Relat Res. No. 401, pp. 10718

Walker, L., Thompson, D., Easton, D., Ponder, B., Ponder, M., Frayling, I. \& Baralle, D. (2006). A prospective study of neurofibromatosis type 1 cancer incidence in the UK. Br J Cancer. Vol. 95, No. 2, pp. 233-8

Wang, Z. \& Liu, Y. (2010). Research update and recent developments in the management of scoliosis in neurofibromatosis type 1. Orthopedics. Vol. 33, No. 5, pp. 335-41

Weixi, W., Nyman, J.S., Moss H., E., Gutierrez G., Mundy G.R., Xiangli Y. \& Elefteriou F. (2010) Local Low-Dose Lovastatin Delivery Improves the Bone-Healing Defect Caused by Loss of Function in Osteoblasts. Journal of Bone and Mineral Research. Vol. 25, No 7, pp. 1658-1667

Williams, V.C., Lucas, J., Babcock, M.A., Gutmann., DH, Korf, B. \& Maria, B.L. (2009). Neurofibromatosis type 1 revisited. Pediatrics; Vol. 123, No. 1, pp. $124-133$

Wozniak, W. \& Karwacki, M.W. (2008). Is "watchful waiting" superior to surgery in children with neurofibromatosis type 1 presenting with extracranial and extramedullary tumor mass at diagnosis? Childs Nerv Syst. Vol. 24, No. 12, pp. 1431-6

Writing Group for the ISCD Position Development Conference: Diagnosis of osteoporosis in men, premenopausal women, and children. (2004). J Clin Densitom. Vol. 7, No. 1, pp. 17-26

Yang, F.C., Chen, S., Clegg, T., Li, X., Morgan, T., Estwick, S.A., Yuan, J., Khalaf, W., Burgin, S., Travers, J., Parada, L.F., Ingram, D.A., Clapp, D.W. (2006). Nf1+/- mast cells induce neurofibroma like phenotypes through secreted TGF-beta signaling. Hum Mol Genet. Vol. 15, No. 16, pp. 2421-2437

Yu, X., Chen, S., Potter, O.L., Murthy, S.M., Li, J., Pulcini, J.M., Ohashi, N., Winata, T., Everett, E.T., Ingram, D., Clapp, W.D. \& Hock, J.M. (2005). Neurofibromin and its inactivation of Ras are prerequisites for osteoblast functioning. Bone. Vol. 36, No. , pp. 793-802 


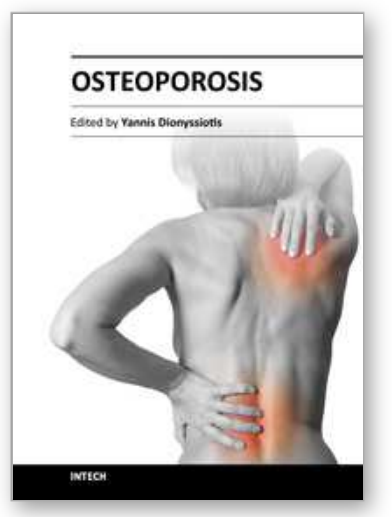

\author{
Osteoporosis \\ Edited by PhD. Yannis Dionyssiotis
}

ISBN 978-953-51-0026-3

Hard cover, 864 pages

Publisher InTech

Published online 24, February, 2012

Published in print edition February, 2012

Osteoporosis is a public health issue worldwide. During the last few years, progress has been made concerning the knowledge of the pathophysiological mechanism of the disease. Sophisticated technologies have added important information in bone mineral density measurements and, additionally, geometrical and mechanical properties of bone. New bone indices have been developed from biochemical and hormonal measurements in order to investigate bone metabolism. Although it is clear that drugs are an essential element of the therapy, beyond medication there are other interventions in the management of the disease. Prevention of osteoporosis starts in young ages and continues during aging in order to prevent fractures associated with impaired quality of life, physical decline, mortality, and high cost for the health system. A number of different specialties are holding the scientific knowledge in osteoporosis. For this reason, we have collected papers from scientific departments all over the world for this book. The book includes up-to-date information about basics of bones, epidemiological data, diagnosis and assessment of osteoporosis, secondary osteoporosis, pediatric issues, prevention and treatment strategies, and research papers from osteoporotic fields.

\title{
How to reference
}

In order to correctly reference this scholarly work, feel free to copy and paste the following:

Marek W. Karwacki and Wojciech Wozniak (2012). The Skeleton Abnormalities in Patients with Neurofibromatosis Type 1: Important Consequences of Abnormal Gene Function, Osteoporosis, PhD. Yannis Dionyssiotis (Ed.), ISBN: 978-953-51-0026-3, InTech, Available from:

http://www.intechopen.com/books/osteoporosis/the-skeleton-abnormalities-in-patients-with-neurofibromatosistype-1-important-consequences-of-abnor

\section{INTECH}

open science | open minds

\author{
InTech Europe \\ University Campus STeP Ri \\ Slavka Krautzeka 83/A \\ 51000 Rijeka, Croatia \\ Phone: +385 (51) 770447 \\ Fax: +385 (51) 686166 \\ www.intechopen.com
}

\author{
InTech China \\ Unit 405, Office Block, Hotel Equatorial Shanghai \\ No.65, Yan An Road (West), Shanghai, 200040, China \\ 中国上海市延安西路65号上海国际贵都大饭店办公楼405单元 \\ Phone: +86-21-62489820 \\ Fax: $+86-21-62489821$
}


(C) 2012 The Author(s). Licensee IntechOpen. This is an open access article distributed under the terms of the Creative Commons Attribution 3.0 License, which permits unrestricted use, distribution, and reproduction in any medium, provided the original work is properly cited. 